\title{
Planning and Development of Higher Vocational Education Institutions in China: Problems and New Policies
}

\author{
Wei Li · Jie Huang
}

Published online: 6 October 2012

(C) CEEUN 2012

\begin{abstract}
Strategic planning is much needed for the development of Higher Vocational Education Institutions (HVEIs) in China in the 21st century. However, HVEIs now has many problems in its strategic planning, which not only existed in the content, but also in the process. For solving the problems, HVEIs need a strategic planning reform. This paper will discusses about how HVEIs can promote the reform, together with an analysis of why they should have the reform and what are their problems. The data used is from some government documents and published papers. In conclusion, we suggest that HVEIs in China need to adhere to the realitybased development logic to improve the content rationality of strategic planning, and also to promote the organizational system and process of accomplishment to improve the work scientificity of strategic planning.
\end{abstract}

Keywords Higher vocational education institution · Strategic planning

\section{Introduction}

Higher vocational education is an essential part in China's educational development, which helps China to realize massification of its higher education and promote its economic and social development. It develops tremendously since the 1990s and up to now it accounts for half of the country's age-appropriate population

This article is a research achievement of the Higher Education Research Base of Zhejiang Province, Zhejiang Normal University, China.

W. Li $(\bowtie)$

College of Education, Zhejiang University, Jinhua, China

e-mail: weiwei860126@126.com

W. Li · J. Huang

Institute of Educational Science, Zhejiang Normal University, Jinhua, China 
in Higher Education. However, accompanying with its rapid growth, a number of Higher Vocational Education Institutions (HVEIs) in China have coming across more and more problems. Meanwhile, as the promulgation and implementation of National Medium and Long Term Educational Reform and Development Project (2010-2020) and Medium and Long-Term Plan on Developing High-Skilled Talent (2010-2020), new developing opportunities are also existing for them. In order to solve the problems, grasp the opportunities and obtain a better development in the 21st century, HVEIs should pay attention to strategic planning and improve their strategic planning capacity. Based upon the present situation of HVEIs in China, this paper will give the reasons why strategic planning is needed for them, analyze the problems which they are facing, and find the countermeasures what they eager for.

Strategic Planning: Why it is Needed for HVEIs in the 21st Century

According to Xiong and Zhengzhou (2009)'s point, strategic planning refers to the planning, arrangement, or expectation, for ensuring, fulfilling and achieving the future developing strategic of higher education institutions for the purpose of maintaining the sustainable development by using modern and advanced technology and measures on the bases of scientific analysis of systematic structure and its variation law of exterior environments and interior elements. It is of great significance to HVEIs in China in 21 st century.

Strategic Planning is What HVEIs Need for Solving Their Problems and Promoting the Quality and Core Competence

Since 1980s, higher vocational education experiences a highly developing period and has already being the essential component of higher education in China. However, the developing model which emphasis on speed and scale causes a series of problems, such as lack of characteristic, low quality, etc. One of the most important reasons for these problems is that HVEIs are short of clear consideration on their developments, and are without systematic planning of their development goals, approaches and measures. Meanwhile, with the enlargement of scale, the promotion of students, promoting the quality and core competence is becoming the key of HVEIs' survival and development in the future. It is needed for them to have a clear realization and systematic planning of their development with scientific processes and methods.

\section{Strategic Planning is What the HVEIs Need for Adhering to the New Situation and Fostering Future Social Development in China}

Higher vocational education has provided China a large number of highly skilled talents in the fields of manufacture, construction, service and management in the last decade, which promotes the socialism modernization construction. Now, China is at the key stage of reform development and commits to achieve the transformation of economic development model and industrial restructuring. Therefore, high quality 
employees and skilled talents are much more needed in the future economic society. As the main force of modern vocational education, HVEIs have to adapt to the contemporary demand. Strategic planning is contributed to achieving the goal. With a view of the formation of the world top short-cycle higher education institutions, strategic planning is the general rule of their success. These institutions always develop a series of proper strategic plans and set strategic goals, by using strategic measures, finally go into the rational development and succeed. At present, Central People's Government (2010) adopts that enhancing educational development strategy research and improving scientific decision-making has already been an essential goal of education development for the period of 2010-2020. As a result, developing strategic planning and promoting institutional development strategy research becomes a new requirement for HVEIs.

The Problems in Strategic Planning: What are HVEIs Now Facing

Strategic planning is not only a process of will inputting and reflecting that affects managing behavior, but also a process of resource redistribution and integration. Generally speaking, strategic planning is composed of two aspects: strategic planning content and strategic planning work. HVEIs in China have problems in both aspects.

\section{Main Problems in Strategic Planning Content}

Strategic planning content contains vision, mission and target system. The target system is composed by core action target and strategic keystone, which have following problems:

Firstly, the strategic core action target is not reasonable enough. The core action target is the key point of strategic planning content, which determines the future developing direction of an institution. However, a number of HVEIs have made mistakes due to the improper concepts or measures. There are mainly three types of this improper. One is regarding level upgrading as the developing strategic target, without practical evaluation of institution development. Since the 21 st century, HVEIs in China are concentrated on upgrading. A number of vocational education institutions are dedicated to be the undergraduate universities. Dai et al. (2005) found that from the year of 1998-2003, there were 114 vocational education institutions or colleges upgrade to undergraduate universities or colleges in China. One is regarding enlarging student number and scale as the developing goal, without consideration of the consequence of running burden. Hui (2007) found that from the year of 2000 to 2005, the number of HVEIs rose from 22 to 54, but only 6 had qualified conditions to run the institutions. Most of them are unsatisfied with teachers, practice training bases, teaching facilities, library resource and so on. The last is regarding plenty and comprehensive of disciplines and majors as the strategic developing goal, without consideration of relationship between discipline, market and social demand. According to Fu (2008)'s research about HVEIs of Guangdong Province, in 2004, there are 60 HVEIs in Guangdong, some majors like "computer application technology" are almost existed in all higher vocational education 
institutions. And, the major setting is almost same among the institutions. Computer, Marketing, Business Administration, Mechanical Manufacturing and Accounting are highly set in the institutions.

Secondly, the strategic development priority is deviated. The development priority of Chinese higher educations is quality improvement rather than scale expansion. Numerous HVEIs put connotation construction as the strategic priority of institutional development, and make a core competence strategy. Nevertheless, due to the incorrect understanding and positioning of core competence, the institutions have developed in two wrong directions which are undergraduate education and secondary-vocational education. The former is highlighted and reinforced in the upsurge of upgrading. Some HVEIs committed to disciplinary education and copy the undergraduate institutions in teaching plan, teaching model and curriculum system. Also, they did not pay attention to explore the characteristic of vocational education but copy the undergraduate institutions in running model and developing forms. The later is particularly appeared in the HVEIs which are upgraded from secondary vocational education institutions. These institutions are heavily affected by secondary education, so they can hardly handle the rules of higher education and answer the basic questions such as how to develop higher vocational education. Their education concepts, manage mechanism and training model are at the level of secondary vocational education. Therefore, some scholar like Yan (2007) points out that although these institutions adopt higher vocational educational system, they provide secondary-vocational-leveled people, not highlevel talented people.

\section{Problems in Strategic Planning Work}

Strategic planning work includes two parts which are organizational system and process of strategic planning. There are problems in both parts of strategic planning work in HVEIs in China.

Firstly, the organizational system of strategic planning is incomplete. On one hand, there is no strategic planning organization. In China, a part of demonstrating HVEIs such as Shenzhen Polytechnic, Ningbo Polytechnic establish institutional research organizations called research department or vocational education research institute which focus on doing research, cooperation between industry and research, and transformation and spread of scientific research achievements. But there is rarely an organization focusing on institutional strategic planning. Because of the absence of professional and systematic institutional research, HVEIs are difficult to do comprehensive and systematic analysis and research on their historical evolution and present status, and difficult to provide basis for accurate position and characteristics of the institutions, then difficult to develop an operative strategy. On the other hand, there is no strategic planning guarantee institution. Guarantee institutions should provide information, statistics and consultation for strategic decision, in order to make sure the scientificity and continuity of the institutional strategic planning. They should include professional committee, expert committee, and other departments. The imperfection of the organizational system in HVEIs and the limit of function and influence of professional organization, are the obstacles of 
evaluation and system guarantee. The absence of guarantee institutions exacerbates the problem of lacking of systematization, development, and scientificity, such as short-term planning (annual planning, annual working priorities, etc.) but not mid-and-long-term developing strategic planning, such as imperfection of systematization and sustainability among strategies, such as the contents of strategy and sub-strategy are inharmonious.

Secondly, the process of strategic planning is out of scientificity. Strategic planning is a continuous, repeated and activity-tendency process according to the institutional vision and mission, which is consisted of three steps: (a) strategic analysis, (b) strategic selection, and (c) strategic solution and evaluation. These steps have clear contents and procedures. A reasonable and scientific strategic planning should be from top to bottom, with careful consideration and be comprehensive. To check the enacting of strategic planning with this criterion, it can be found that strategic planning of most HVEIs is out of scientificity. Yang (2005) found that the developing strategy for one HVEI in Henan Province was based on the decision towards transforming period made by leaders of the institution. The institution establishes a characteristic construction leading team which is represented by main leaders of the institution, enacts strategic contents with professional, management, technology and enrollment and employment characters, and implement in different levels. The enacting process has many problems. The "from top to bottom" model of enacting process goes without assessment about pre-strategy, without assessment according to the willingness, mission and confronted situation and problems, and without enough consideration of the participation, supervision and assessment of the stakeholders like students, teachers and administrative staffs, local industry and commerce.

\section{Countermeasures in Strategic Planning: How Could HVEIs Do}

According to the problems, HVEIs in China need systematic improvement in their strategic planning by reasonable planning content and scientific planning work.

\section{Based on the Fact, Reinforce the Reasonability of Strategic Planning Content}

First of all, HVEIs should be aware of its position in the systems of vocational education and higher education, and make the function and goal clear. Training skilled talents is the main the function for HVEIs. Compare with undergraduate colleges and universities, HVEIs are specialized in training highly skilled talents, which are also needed for the society. HVEIs should take it as the goal by the combination of industry, education and research, combination of work and study, cooperation of school and corporation, contrasting internship and other training model and concrete measures. Compare with secondary vocational education institutions, HVEIs should work at exploring the training mode of compound talents, innovative talents, realizing the introductory and guiding function of vocational education in talent training and education, as well as the educational function of meeting social needs, spreading and building industrial civilization and 
corporate culture, which is closer to reality than undergraduate education, and wiser than secondary vocational education.

Secondly, HVEIs should base on themselves and society, and make sure of the intension of the core competence and institutional characteristics. Generally speaking, core competence is constituted of three elements of resources (human resources, material resources), culture (spiritual culture, material culture, institutional culture) and capacity (talents training, scientific study, and social service). HVEIs should confirm the meaning of core competitiveness according to the analysis about institutional condition and social need. The meaning of core competence should have specialty and reasonability, such as core competence on industry with local specialty, core competence on establishing mature training mode of work-andstudy combination and school-and corporate cooperation, core competence that joins secondary vocational, higher vocational and lifelong education together, and core competence based on the pioneering idea. Take Zhejiang Industry Polytechnic College for example, the local development of the yellow rice wine needs forefront, highly skilled and innovative talents that participate in the line of brewage, marketing, management and service. The college is based on the self-outstanding running basis and condition, and establishes the only "yellow rice wine college" in China with the local famous yellow rice wine corporate. The college confirms the core competitive intension based on the industry with local specialty, and becomes the base of training highly skilled talents in the industry of yellow rice wine.

\section{Improve the System, and Promote the Scientificity of Strategic Planning Work}

HVEIs should reinforce the strategic planning work, and improve the scientificity. There are two significations of reinforcing the strategic planning work.

Firstly, HVEIs need to improve the organizational system of strategic planning. It contains enacting institutions and guarantee institutions of strategic planning. HVEIs should establish special institutional research organization and strength the sense of planning. The institutional research team should be well educated, with diversified professional background and certain work experience. Meanwhile, the team members should have capacity of mutual learning, deep problem-insight, and sufficient background capacity of school-based knowledge. On the other hand, HVEIs should found special guarantee organizations to guarantee the strategic planning. They should spontaneously set some organizational units, such as academic organization or professional organization, coordinate the running of HVEIs, improve the strategic planning capacity and guarantee the quality of higher vocational education by activities such as identification, judgment and supervision.

Secondly, HVEIs should promote the process of accomplishment of strategic planning. This means HVEIs should enact strategies through scientific, reasonable procedure and measures. The procedure can be consisted of the following steps: (a) topic set, which consist of three steps of building a strategic planning leading team; setting topic by Investigation and analysis; and setting main strategic questions. (b) strategic fixing, which consist of ten steps of analyzing main strategic questions and providing engineering report; preparing a strategic draft and committing to the leading team; Auditing by the leading team and committing to 
the decision making departments for discuss and revision; distributing the revised draft and asking for opinions; final revising, committing, and fixing the strategic planning; distributing the planning to departments and forming sub-strategic planning; optimizing and fixing the general strategy and sub-strategy. Nothing but scientific and reasonable procedure and measures for enacting strategic planning can make sure the scientificity, reasonability and effectiveness of a developing strategy.

\section{References}

Central People"s Government (2010) National medium and long term educational reform and development project (2010-2020). http://www.gov.cn/jrzg/2010-07/29/content_1667143.htm. Retrieved 20 March 2012

Dai JG et al (2005) Analysis of layout structure of chinese higher education institutions. Explor Educ Dev 9:5-11

Fu X (2008) Comparative study on the development of tertiary vocational and technical education during the course of the massification of higher education. East China Normal University, Shanghai

Hui L (2007) Analyses and countermeasures of the development of higher vocational education in Anhui Province. HeFei University of Technology, HeFei

Xiong Zhou, Zhengzhou Zhao (2009) The problem and countermeasure facing to the implementation of university strategic planning. J Huazhong Agric Univ (Soc Sci Edn) 26:53-56

Yan X (2007) General college education system is not a good choice for higher vocational education. Vocat Tech Educ Forum 17:4-6

Yang Z (2005) On the practice of characteristic construction in higher vocational schools: taking Hebi College of Vocation and Technology as an example. Vocat Tech Educ 26:39-42 